\title{
Utilization of konjac glucomannan as a fat replacer in low-fat and skimmed yogurt
}

\author{
Shuhong Dai, ${ }^{*}$ Harold Corke, ${ }^{*} \dagger$ and Nagendra P. Shah ${ }^{* 1}$ \\ ${ }^{*}$ Food and Nutritional Sciences, School of Biological Sciences, The University of Hong Kong, Pokfulam Road, Hong Kong, Pokfulam 0000 \\ †Department of Food Science and Technology, Shanghai Jiao Tong University, Shanghai, 200240, PR China
}

\begin{abstract}
Konjac glucomannan (KGM) has been reported to be beneficial to human health, as well as having potential functional properties as a fat replacer in dairy products. In this study, $0.5 \% \mathrm{KGM}$ solution was added to prepare low-fat (LFKGM) and skimmed (SKKGM) yogurts, and their physicochemical properties were compared with those of full-fat yogurt control (FFC), low-fat yogurt control (LFC), and skimmed yogurt control (SKC). Properties and composition were determined and the microscopic structures of all yogurts were observed during storage at $4^{\circ} \mathrm{C}$ for $21 \mathrm{~d}$. Generally, addition of KGM to yogurts had no significant effect on composition, $\mathrm{pH}$, and titratable acidity at each storage day. The LFKGM and SKKGM had higher whiteness, greenness, and yellowness hues compared with those of the LFC and SKC. The proteolysis of LFKGM and SKKGM was similar to that of FFC, whereas it was lower than in LFC and SKC after $14 \mathrm{~d}$ of storage. Addition of KGM had no positive effects on the waterholding capacity, but led to a decrease in syneresis and spontaneous whey separation in LFKGM and SKKGM compared with those of LFC and SKC. The spontaneous whey separation of LFKGM was similar to that of FFC. Presence of KGM in skimmed yogurt affected textural characteristics, while having little effect on texture of low-fat yogurt. Additionally, LFKGM and SKKGM showed stronger and more stable gel structures than those of FFC, LFC, and SKC. Overall, no substantial changes were found in the characteristics for each yogurt during storage, except for $\mathrm{pH}$ and gel structures. Results indicated that KGM may be a good fat replacer to develop reduced-fat yogurts with desired characteristics.
\end{abstract}

Key words: konjac glucomannan, yogurt, physiochemical property, texture, structure

Received March 3, 2016

Accepted May 24, 2016.

${ }^{1}$ Corresponding author: npshah@hku.hk

\section{INTRODUCTION}

Yogurt is a popular dairy product obtained by lactic acid fermentation of milk. High milk fat diets are associated with high serum cholesterol levels, digestive disorders, heartburn, and stress (Ünal et al., 2003). The awareness of the harmful effects of excess fat consumption on human health has led consumers to demand low-fat or nonfat dairy products (Aziznia et al., 2008). However, the presence of fat in dairy products is important for their physical properties, rheological, and textural characteristics; in addition, fat influences other product characteristics such as appearance, flavor, and mouthfeel (Brennan and Tudorica, 2008). Separation of whey and variations in viscosity are 2 primary defects in yogurts, especially in low-fat yogurt. Some reports suggest that certain dairy ingredients and hydrocolloids could be added to combat these defects (Keogh and O'Kennedy, 1998). Carbohydrate-based fat replacers can be used in yogurt for improving its functionality, such as binding of water and increasing viscosity (Tamime and Robinson, 1999).

Fat-free yogurt with 1\% inulin added showed similar characteristics to a control yogurt containing $3 \%$ milk fat, but increased addition of inulin (2 and $3 \%$ ) had negative effects on some physical properties, such as whey separation, consistency, and organoleptic scores (Guven et al., 2005). Other studies report that addition of gum tragacanth did not improve the firmness of nonfat yogurt. Increasing amount of gum led to softer gels with more syneresis, and coarser and more open structure compared with the control nonfat yogurt (Aziznia et al., 2008). Native maize starch was added to reduced-fat yogurt, resulting in lower syneresis than in full-fat yogurt, and contributing to the formation of more stable dispersed acidified milk gelled systems (Lobato-Calleros et al., 2014). However, we were unaware of any published report on the use of konjac glucomannan (KGM) in the manufacture of low-fat or skimmed yogurt.

Konjac glucomannan is extracted from the tubers of Amorphophallus konjac, a member of the family 
Araceae found in East Asia, and it is a neutral heteropolysaccharide that has been widely used in food products (Nishinari et al., 1992). Konjac glucomannan is a linear random copolymer of 1,4-linked $\beta$-D-mannose and $\beta$-D-glucose at a molar ratio of $1.6: 1$ with a low degree of acetyl groups at the C-6 position and also certain short-chain branches at C-3 position of the mannoses (Kato and Matsuda, 1969). Konjac glucomannan is dispersible in hot or cold water and forms a highly viscous solution (Vanderbeek et al., 2007). Konjac glucomannan is beneficial to human health and is reported to prevent some diseases (Vuksan et al., 1999; James and Follett, 2000; Fang and Wu, 2004). It is reported that KGM has antiobesity and antihyperglycemic properties due to promotion of satiety, delay in stomach emptying, retarded bowel transit time, and subsequent reduced rate of dietary sugar absorption; these can reduce the elevation of postprandial glucose and insulin surge levels (Fang and Wu, 2004; Kraemer et al., 2007; Chua et al., 2010). As a soluble dietary fiber, KGM also exhibits an anti-hypercholesterolemia property by transferring bile acids bound with KGM out of human body; this leads to the body to convert more cholesterol into bile acids (Fang and Wu, 2004; Chua et al., 2010; Abhyankar et al., 2011). Additionally, it was reported that KGM also has laxative effect, prebiotic, and anti-inflammatory properties ( $\mathrm{Li}$ et al., 2005; Chua et al., 2010; Abhyankar et al., 2011). These properties of KGM make it a potential fat replacer for use in dairy products.

In this study, KGM was added to milk to make lowfat and skimmed yogurts to investigate the possibility of using KGM as a fat replacer. The effects of KGM addition on physicochemical properties, texture parameters, and serum expulsion of low-fat and skimmed yogurt during storage were investigated.

\section{MATERIALS AND METHODS}

\section{Materials}

Fresh whole, low-fat, and skimmed cow milk were obtained from a local milk company (Farm Milk Company Limited, Hong Kong). The protein and fat contents of each kind of milk were $3.6,3.8$, and $3.6 \mathrm{~g} / 100 \mathrm{~mL}$ and $5.1,2.5$, and $0.7 \mathrm{~g} / 100 \mathrm{~mL}$, respectively. Konjac purified flour (KJ30, KGM content $\geq 85 \%$ ) was obtained from Hubei Konson Konjac Gum Co., Ltd. (Wuhan, Hubei Province, China).

\section{Activation of Starter Culture}

Streptococcus thermophilus (ST) 1303 and Lactobacillus bulgaricus (LB) 859 were originally obtained from the Starter Culture Collection of Dairy Innovation Australia Ltd. (ASCC, Werribee, Victoria, Australia; now Chr. Hansen, Werribee, Victoria, Australia). The stock of ST 1303 and LB 859 were first activated by growing in sterile M17 broth and de Man, Rogosa, Sharpe broth 3 times, respectively, and then propagated using $12 \%$ (wt/wt) sterile reconstituted skim milk at $37^{\circ} \mathrm{C}$ for $24 \mathrm{~h}$ in triplicate. Enumeration of each bacterium was carried out using plate count method before used as starters in following yogurt preparation part. For the plate count determination, serial $10 \times$ dilutions of ST 1303 and LB 859 stocks were carried out in sterile $0.85 \%$ saline. Subsequently, $50-\mu \mathrm{L}$ aliquots of ST 1303 or LB 859 serial dilutions were poured into M17 or de Man, Rogosa, Sharpe agar plates, respectively, and then the plates were incubated at $37^{\circ} \mathrm{C}$ for $24 \mathrm{~h}$. Plates showing 25 to 250 colonies were counted and results were expressed as colony-forming units per milliliter of the inoculated sample.

\section{Yogurt Preparation}

Konjac glucomannan solution $(0.5 \%)$ was prepared by dissolving konjac purified flour in sterile Milli-Q water and stored overnight at $4^{\circ} \mathrm{C}$ before use. Yogurt mix was prepared by mixing $28.5 \mathrm{~mL}$ of milk and 1.5 $\mathrm{mL}$ of Milli-Q water or $0.5 \%$ KGM solution in a $50-\mathrm{mL}$ tube at $22^{\circ} \mathrm{C}$ for $2 \mathrm{~h}$ using a shaker according to Table 1. Full-fat yogurt control (FFC), low-fat yogurt control (LFC), skimmed yogurt control (SKC), low-fat yogurt with KGM (LFKGM), and skimmed yogurt with KGM (SKKGM) were then made as follows: yogurt mixes were heated at $85^{\circ} \mathrm{C}$ for 30 min using a water bath with a shaker and cooled to $45^{\circ} \mathrm{C}$, followed by inoculating with $1 \%$ (vol/vol) activated ST 1303 and $1 \%$ (vol/vol) LB 859 and incubation at $42^{\circ} \mathrm{C}$ until $\mathrm{pH}$ decreased to about 4.5. Both ST 1303 and LB 859, which were enumerated by plate count as mentioned above, were diluted to $1 \times 10^{9} \mathrm{cfu} / \mathrm{mL}$ with sterile reconstituted skim milk before inoculation. The yogurts were stored at $4^{\circ} \mathrm{C}$; properties and composition were tested at $0,7,14$, and $21 \mathrm{~d}$ during storage. All yogurts produced were set-style.

\section{Composition and Color Analysis}

Compositional analysis was carried out after $24 \mathrm{~h}$ of storage after yogurt preparation. Protein, fat, and TS were analyzed using the Kjeldahl, Babcock, and oven drying methods, respectively (AOAC International, 1999). The $\mathrm{L}^{*}$ (lightness), $\mathrm{a}^{*}$ (red/greenness), and $\mathrm{b}^{*}$ (yellow/blueness) values were measured using a Minolta Chroma Meter at $4^{\circ} \mathrm{C}$ (CR-300 Series, Minolta, Osaka, Japan). 


\section{pH and Titratable Acidity Measurement}

A pH meter (model 250A, Science International Corporation, Hong Kong) was used to measure the changes in $\mathrm{pH}$ of the product. The $\mathrm{pH}$ meter was calibrated with fresh $\mathrm{pH} 4.00$ and 7.00 standard buffers and samples were tempered to $22^{\circ} \mathrm{C}$ before measurement.

Titratable acidity (TA) of yogurts was measured according to the AOAC titration method (AOAC International, 1999). Briefly, $9.0 \mathrm{~g}$ of yogurt sample was diluted with equal amount of Milli-Q water and $0.1 \mathrm{M}$ $\mathrm{NaOH}$ was used for titration using phenolphthalein as indicator. The TA was expressed as percent lactic acid as follows:

$$
\text { Lactic acid } \%=\mathrm{V} \times 0.009 / \mathrm{W} \times 100,
$$

where $\mathrm{V}$ is the volume of $0.1 \mathrm{MNaOH}(\mathrm{mL})$ and $\mathrm{W}$ is the weight of yogurt (g).

\section{Extent of Proteolysis}

Filtrates of the yogurt samples were prepared as per Ramchandran and Shah (2010) by centrifuging the yogurts at $4,000 \times g$ for $30 \mathrm{~min}$ at $4^{\circ} \mathrm{C}$, and then the supernatants were filtered through $0.45-\mu \mathrm{m}$ PTFE Acrodisc CR syringe membrane filters (Pall Corporation, New York, NY) and stored at $-20^{\circ} \mathrm{C}$ until assayed.

The extent of proteolysis was determined by the free AA content in filtrates of yogurt samples using the $o$ phthaldialdehyde (OPA) method according to Church et al. (1983) with some modification. Briefly, $50 \mu \mathrm{L}$ of filtrate was added to $1 \mathrm{~mL}$ of OPA reagent and vortexed for $5 \mathrm{~s}$, followed by measuring absorbance value at 340 nm within 2 min using a UV-VIS spectrophotometer (Shimadzu Scientific Instruments, Kyoto, Japan). The readings of the reagent blank were deducted from the corresponding readings of yogurt samples to obtain the amount of free AA released as a consequence of the proteolytic capacities of the starter cultures during fermentation and storage.

\section{Whey Expulsion Measurement}

Water-Holding Capacity. The water-holding capacity (WHC) of yogurts was measured according to Sahan et al. (2008) with some modification. To determine WHC of the yogurts, $5 \mathrm{~g}$ of yogurt samples was centrifuged at 4,713 $\times g$ (Hitachi high-speed refrigerated centrifuge, model GR22G, Hitachi Ltd., Tokyo, Japan) for $30 \mathrm{~min}$ at $4^{\circ} \mathrm{C}$. After centrifugation, the supernatant was collected and weighed. The WHC was calculated as 1 minus the percent weight of the supernatant over the initial weight of the yogurt samples.

Syneresis. Measurement of syneresis was carried out by the drainage method according to Tamime et al. (1996) with some modifications. Briefly, about 25 g of yogurt sample was weighed on a no. 4 filter paper (qualitative, catalog no. 1004 125, Whatman, Maidstone, UK) placed on the top of a funnel. Syneresis of whey was measured by gravity at $4^{\circ} \mathrm{C}$ for $120 \mathrm{~min}$ and the syneresis value was calculated as the percent weight of whey collected in a flask divided by the initial weight of the yogurt sample.

Spontaneous Whey Separation. Spontaneous whey separation (SWS) of undisturbed set yogurts was carried out by siphon method according to Lucey et al. (1998) with some modifications. Briefly, the weight of a tube of yogurt taken out from $4^{\circ} \mathrm{C}$ was recorded immediately and then the collected whey at the side of the tube was siphoned out with a pipette within $10 \mathrm{~s}$ by keeping the tube at an angle of approximately $45^{\circ}$. The SWS is expressed as the percent weight of the whey over the initial weight of the yogurt.

\section{Texture Analysis}

Texture measurements of yogurt were carried out with a TA.XT Plus model Texture Analyzer (Stable Micro Systems, Godalming, Surrey, UK) with a 5-kg load cell. A tube of yogurt sample was taken out from $4^{\circ} \mathrm{C}$, and the whey on the surface was siphoned out. A 20-mm-diameter probe (A/BE20) was used, and when

Table 1. Yogurt mix composition before fermentation

\begin{tabular}{|c|c|c|c|c|c|}
\hline \multirow[b]{2}{*}{ Sample } & \multicolumn{5}{|c|}{ Yogurt mix composition } \\
\hline & $\begin{array}{l}\text { Full-fat } \\
\text { milk (mL) }\end{array}$ & $\begin{array}{l}\text { Low-fat } \\
\text { milk }(\mathrm{mL})\end{array}$ & $\begin{array}{c}\text { Skim } \\
\text { milk }(\mathrm{mL})\end{array}$ & $\begin{array}{l}\text { Water } \\
(\mathrm{mL})\end{array}$ & $\begin{array}{c}0.5 \% \mathrm{KGM}^{1} \\
\text { solution }(\mathrm{mL})\end{array}$ \\
\hline Full-fat yogurt control & 28.5 & - & - & 1.5 & - \\
\hline Low-fat yogurt control & - & 28.5 & - & 1.5 & - \\
\hline Skimmed yogurt control & - & - & 28.5 & 1.5 & - \\
\hline Low-fat yogurt with KGM & - & 28.5 & - & - & 1.5 \\
\hline Skimmed yogurt with KGM & - & - & 28.5 & - & 1.5 \\
\hline
\end{tabular}

${ }^{1} \mathrm{KGM}=$ konjac glucomannan. 
a 10-g surface trigger was attained, the probe started to penetrate to a depth of $30 \mathrm{~mm}$ at a constant crosshead speed of $1.0 \mathrm{~mm} / \mathrm{s}$. From the resulting force-time curve, the values for texture attributes were analyzed using the Exponent version 6.1.4.0 equipment software (Lotun Science Co Ltd., Beijing, China).

\section{Microscopic Structures}

Microscopic structures of yogurt were observed by a confocal laser scanning microscopy (CLSM) with multiphoton system (LSM710 NLO, Carl Zeiss, Jena, Germany). For staining yogurt samples, $20 \mu \mathrm{L}$ of Nile red $(1 \mathrm{mg} / \mathrm{mL}$ in ethanol) and $20 \mu \mathrm{L}$ of fluorescein isothiocyanate $(1 \mathrm{mg} / \mathrm{mL}$ in ethanol) were mixed with a 1-mL yogurt sample for $30 \mathrm{~min}$. Afterward, $50 \mu \mathrm{L}$ of stained sample was pipetted to a glass slide and sealed with a coverslip before observation. Nile Red and fluorescein isothiocyanate were excited at the excitation/ emission wavelengths of $534 \mathrm{~nm} / 500$ to $600 \mathrm{~nm}$ and 488 $\mathrm{nm} / 495$ to $559 \mathrm{~nm}$, respectively.

\section{Statistical Analysis}

Data reported are mean \pm standard deviation for triplicate determinations of each yogurt. One-way ANOVA and Tukey's test at 95\% confidence intervals $(P<0.05)$ were performed using IBM SPSS Statistics 20.0 (Armonk, NY). Tukey's tests were applied for different yogurt at each storage time and for each yogurt at different storage times.

\section{RESULTS AND DISCUSSION}

\section{Composition and Color}

The composition of yogurt samples is shown in Table 2. The TS of FFC was higher than other yogurt samples, whereas there was no significant difference among LFC, SKC, LFKGM, and SKKGM. Fat content of FFC was higher than other yogurt samples, with no significant differences among fat contents of LFKGM and SKKGM as compared with those of LFC and SKC. Protein contents of yogurt samples ranged between 4.82 and $5.03 \%$, which were higher than those in milk. Aziznia et al. (2008) and Dinkci (2012) also reported the higher protein content in yogurt than in milk. The increased protein content in yogurt may be because of the evaporation during and increased bacterial mass during fermentation (Deeth and Tamime, 1981). The bacterial cell mass constitutes about $1 \%$ of the DM in yogurt, which is a rich source of EAA (Erdman et al., 1977; Deeth and Tamime, 1981; Park, 2000). The evaporation could cause the loss of weight of yogurt, which may have also resulted in an increase of protein percentage in the yogurt. The composition results indicated that the overall composition was not changed by the low level addition of KGM in low-fat or skimmed yogurt. According to our previous work (unpublished data), when the concentration of KGM solution was more than $0.5 \%$, a metastable or unstable state of the KGM-milk mixtures was observed at the level of $95 \%$ milk. Additionally, phase separation was observed in yogurts prepared with the metastable or unstable KGM-milk mixtures; this would be unacceptable in practice.

Color plays an important role in food choice for consumers. The color attributes of yogurt samples are also shown in Table 2. The $\mathrm{L}^{*}$ value represents lightness (100) and blackness (0), and is an estimation of food whiteness (Zare et al., 2011). No difference was present among $\mathrm{L}^{*}$ values of FFC, LFKGM, and SKKGM and they were higher than those of LFC and SKC. No difference was found in $\mathrm{L}^{*}$ values of LFC and SKC. The results illustrated that the addition of KGM in low-fat or skimmed yogurt enhanced the whiteness of yogurts, which provided whiteness similar to that of full-fat yogurt. The $a^{*}$ and $b^{*}$ values represented red-green (positive-negative) and yellow-blue (positive-negative) hues of the yogurt samples (Sanz et al., 2008). Param-

Table 2. Composition and color of yogurts ${ }^{1}$

\begin{tabular}{|c|c|c|c|c|c|c|}
\hline \multirow[b]{2}{*}{ Sample $^{2}$} & \multirow[b]{2}{*}{$\mathrm{TS}(\%)$} & \multirow[b]{2}{*}{ Fat $(\%)$} & \multirow[b]{2}{*}{ Protein (\%) } & \multicolumn{3}{|c|}{ Color } \\
\hline & & & & $\mathrm{L}^{*}$ & $a^{*}$ & $\mathrm{~b}^{*}$ \\
\hline $\mathrm{FFC}$ & $17.69 \pm 1.79^{\mathrm{a}}$ & $5.78 \pm 0.27^{\mathrm{a}}$ & $4.93 \pm 0.05^{\mathrm{ab}}$ & $84.46 \pm 1.27^{\mathrm{ab}}$ & $-5.70 \pm 0.10^{\mathrm{a}}$ & $2.98 \pm 0.21^{\mathrm{b}}$ \\
\hline $\mathrm{LFC}$ & $10.53 \pm 0.46^{\mathrm{b}}$ & $2.65 \pm 0.28^{\mathrm{b}}$ & $4.82 \pm 0.04^{\mathrm{b}}$ & $79.79 \pm 1.45^{b c}$ & $-5.53 \pm 0.06^{\mathrm{a}}$ & $1.07 \pm 0.18^{\mathrm{c}}$ \\
\hline $\mathrm{SKC}$ & $10.73 \pm 0.56^{\mathrm{b}}$ & $0.83 \pm 0.28^{\mathrm{c}}$ & $4.92 \pm 0.03^{\mathrm{ab}}$ & $76.62 \pm 0.77^{\mathrm{c}}$ & $-5.73 \pm 0.19^{\mathrm{a}}$ & $1.59 \pm 0.74^{\mathrm{c}}$ \\
\hline LFKGM & $10.85 \pm 0.08^{\mathrm{b}}$ & $1.65 \pm 0.29^{\mathrm{bc}}$ & $4.96 \pm 0.04^{\mathrm{a}}$ & $84.49 \pm 1.61^{\mathrm{ab}}$ & $-6.14 \pm 0.21^{\mathrm{b}}$ & $3.71 \pm 0.97^{\mathrm{ab}}$ \\
\hline SKKGM & $10.19 \pm 0.39^{b}$ & $0.66 \pm 0.28^{\mathrm{c}}$ & $5.03 \pm 0.07^{\mathrm{a}}$ & $85.92 \pm 0.83^{\mathrm{a}}$ & $-6.24 \pm 0.02^{\mathrm{b}}$ & $4.85 \pm 0.41^{\mathrm{a}}$ \\
\hline
\end{tabular}

\footnotetext{
${ }^{a-c}$ Means in each parameter without common superscripts are significantly different $(P<0.05)$.

${ }^{1}$ Values are expressed as mean $\pm \mathrm{SD}, \mathrm{n}=3$.

${ }^{2} \mathrm{FFC}=$ full-fat yogurt control; LFC = low-fat yogurt control; SKC = skimmed yogurt control; LFKGM = low-fat yogurt with KGM; SKKGM = skimmed yogurt with KGM; KGM = konjac glucomannan.
} 
Table 3. $\mathrm{pH}$ and titratable acidity (\%) of yogurts during $21 \mathrm{~d}$ of storage at $4^{\circ} \mathrm{C}^{1}$

\begin{tabular}{|c|c|c|c|c|}
\hline Sample $^{2}$ & \multicolumn{4}{|c|}{ Period of storage (d) } \\
\hline \multicolumn{5}{|l|}{$\mathrm{pH}$} \\
\hline LFC & $4.50 \pm 0.04^{\mathrm{A}}$ & $4.32 \pm 0.04^{\mathrm{B}}$ & $4.23 \pm 0.05^{\mathrm{B}}$ & $4.20 \pm 0.04^{\mathrm{B}}$ \\
\hline $\mathrm{SKC}$ & $4.49 \pm 0.03^{\mathrm{A}}$ & $4.33 \pm 0.04^{\mathrm{B}}$ & $4.24 \pm 0.05^{\mathrm{B}}$ & $4.23 \pm 0.03^{\mathrm{B}}$ \\
\hline LFKGM & $4.53 \pm 0.04^{\mathrm{A}}$ & $4.35 \pm 0.03^{\mathrm{B}}$ & $4.26 \pm 0.04^{\mathrm{BC}}$ & $4.22 \pm 0.03^{\mathrm{C}}$ \\
\hline FFC & $0.782 \pm 0.057^{\mathrm{a}, \mathrm{B}}$ & $0.868 \pm 0.003^{\mathrm{a}, \mathrm{AB}}$ & $0.894 \pm 0.011^{\mathrm{a}, \mathrm{A}}$ & $0.882 \pm 0.003^{\mathrm{a}, \mathrm{A}}$ \\
\hline LFC & $0.816 \pm 0.028^{\mathrm{a}, \mathrm{A}}$ & $0.857 \pm 0.025^{\mathrm{ab}, \mathrm{A}}$ & $0.897 \pm 0.008^{\mathrm{a}, \mathrm{A}}$ & $0.904 \pm 0.011^{\mathrm{a}, \mathrm{A}}$ \\
\hline $\mathrm{SKC}$ & $0.806 \pm 0.079^{\mathrm{a}, \mathrm{A}}$ & $0.861 \pm 0.017^{\mathrm{a}, \mathrm{A}}$ & $0.881 \pm 0.025^{\mathrm{ab}, \mathrm{A}}$ & $0.888 \pm 0.013^{\mathrm{ab}, A}$ \\
\hline LFKGM & $0.801 \pm 0.066^{\mathrm{a}, \mathrm{A}}$ & $0.837 \pm 0.019^{\mathrm{ab}, \mathrm{A}}$ & $0.893 \pm 0.022^{\mathrm{ab}, \mathrm{A}}$ & $0.843 \pm 0.012^{\mathrm{ab}, A}$ \\
\hline SKKGM & $0.759 \pm 0.078^{\mathrm{a}, \mathrm{B}}$ & $0.802 \pm 0.008^{\mathrm{b}, \mathrm{AB}}$ & $0.843 \pm 0.017^{\mathrm{b}, \mathrm{A}}$ & $0.847 \pm 0.007^{\mathrm{b}, \mathrm{A}}$ \\
\hline
\end{tabular}

eters $\mathrm{a}^{*}$ and $\mathrm{b}^{*}$ showed that all the yogurt samples had greenish (negative $\mathrm{a}^{*}$ values) and yellowish (positive $\mathrm{b}^{*}$ values) characteristics. No difference was found in $a^{*}$ values of LFKGM and SKKGM and these were more negative than those of FFC, LFC, and SKC, which presented with a greener hue than the control yogurts. No difference was present in $\mathrm{a}^{*}$ values of FFC, LFC, and $\mathrm{SKC}$, indicating that the fat content had no effect on the greenness of yogurt. The $b^{*}$ values of LFKGM and SKKGM were higher than those of FFC, LFC and SKC, which indicated that the addition of KGM increased yellowness of yogurts. The increased yellowish hue of yogurts with KGM may be because of the Maillard reaction in milk-KGM mixture when heated at $85^{\circ} \mathrm{C}$ for $30 \mathrm{~min}$ for pasteurization and the light brownish color of KGM powder used in our study. Additionally, Park (1996) also reported that the addition of konjac flour increased lightness and yellow hue $\left(b^{*}\right)$ of surimi gels, whereas the green hue (negative $a^{*}$ ) was not affected by the addition of konjac flour.

\section{Changes in $\mathrm{pH}$ and TA}

The $\mathrm{pH}$ and TA of yogurts during storage at $4^{\circ} \mathrm{C}$ are shown in Table 3. The pH of all the yogurts decreased during $21 \mathrm{~d}$ of storage, with a significant decrease occurring at $\mathrm{d} 7$, and stable $\mathrm{pH}$ after $14 \mathrm{~d}$ of storage. Similar observations were reported by Guven et al. (2005) and Sahan et al. (2008) in skimmed yogurt with addition of inulin and $\beta$-glucan, respectively. García-Pérez et al. (2005) also reported that $\mathrm{pH}$ of yogurt with and without orange fiber decreased with storage time, with the decrease more evident during the first $14 \mathrm{~d}$ of storage. Additionally, Beal et al. (1999) observed that the $\mathrm{pH}$ decreased mainly by d 7 , and was due to the increase in lactic acid caused by the high bacterial metabolic activity due to hydrolysis of lactose. Similarly, the level of TA increased slightly during the $21 \mathrm{~d}$ of storage at $4^{\circ} \mathrm{C}$ for all the yogurts. The addition of KGM did not affect the trend of $\mathrm{pH}$ and $\mathrm{TA}$ changes in low-fat or skimmed yogurt, likely because it did not adversely affect the activity of starter bacteria in yogurt (Barrantes et al., 1994).

\section{Extent of Proteolysis}

Extent of proteolysis, representing the proteolytic capabilities of bacteria, is related to the growth of bacteria and acidification of yogurts (Ramchandran and Shah, 2010). Proteolysis of all the yogurt samples increased during $21 \mathrm{~d}$ of storage (Figure 1) and had no significant differences at d 14 and 21 among treatment. The LFC showed continued increase in proteolysis at $\mathrm{d}$ 7 and 14, but the increase in proteolysis occurred only at $\mathrm{d} 7$ for LFKGM and SKKGM, and only at d 14 for FFC. Proteolysis of SKC showed no significant differences between $\mathrm{d} 0$ and $7, \mathrm{~d} 7$ and 14, and $\mathrm{d} 14$ and 21 of storage. Proteinase and peptidases in lactic acid bacteria are related to the proteolysis of caseins (Shihata and Shah, 2000) and this function could provide peptides and AA for the survival of ST 1303 and LB 859 in yogurts continuously. Those proteinase and peptidases could hydrolyze the milk proteins, which resulted in an increase in the amount of the free amino groups that was quantified by the OPA method. Generally, the proteolysis of yogurts increased during the early $14 \mathrm{~d}$ storage and then became stable at d 21 (Figure 1). It may be because the bacteria were unable to use all peptides 
and AA that were liberated from casein, which resulted in increased accumulated peptides and AA during early $14 \mathrm{~d}$ storage ( $\mathrm{Li}$ and Shah, 2015). Furthermore, the liberation and consumption of peptide and AA were balanced, which may result in stable proteolysis during the storage between d 14 and 21. Proteolysis of FFC was the lowest among the yogurt samples during $21 \mathrm{~d}$ of storage. No difference was found in the proteolysis of LFC as compared with that of SKC, and no differences were found between LFKGM and SKKGM at d 7, 14, and 21. This indicated that fat content did not affect the proteolytic capability of the reduced-fat yogurt after $7 \mathrm{~d}$ of storage, whereas proteolysis of LFKGM and SKKGM showed no differences compared with those of LFC and SKC at d 0 and 7, respectively. The LFKGM and SKKGM had lower proteolytic capability than those of LFC and SKC, and had similar proteolysis with FFC at d 14 and 21. Perols et al. (1997) reported that the protein release from KGM hydrogel remained low, and the contraction of the KGM gel solidifies droplets, thus prohibiting the proteolytic enzyme release, and the low enzyme release in whey led to premature decrease in proteolysis. These may be the reason that the proteolysis of yogurts with KGM was lower than that without KGM after $14 \mathrm{~d}$ of storage in our study.

\section{Expulsion of Serum}

Water-Holding Capacity. The WHC measured by centrifugation method represents the level of whey separated from the collapsed gels as a result of centrifugal force (Amatayakul et al., 2006). Higher WHC represents less whey separated from the yogurt by centrifugation. The WHC of FFC was the highest whereas that of SKC was the lowest among the yogurt samples during $21 \mathrm{~d}$ of storage (Figure 2). The WHC of LFC was higher than those of SKC, LFKGM, and SKKGM during $21 \mathrm{~d}$ of storage, except that of LFKGM at d 21, which had no significant difference with LFC, whereas WHC of SKKGM was similar to SKC during $21 \mathrm{~d}$ of storage, except that the WHC at d 14 was higher than SKC. The results illustrated that fat content was the main factor that influenced the WHC of collapsed gels in yogurts, and KGM had no positive effect on WHC in low-fat or skimmed yogurt. Centrifugation method is likely to accelerate the phase separation between milk protein and polysaccharide in yogurt. The whey collected as a result of centrifugation would not only be influenced by the cross-linking of milk proteins with polysaccharides but also some factors such as rigidity and rheological properties of yogurt gels (Amatayakul et al., 2006). In our study, the final percentage of KGM in our yogurt was $0.025 \%$, which could be too low to show the acceleration effects of centrifugation. Addi-

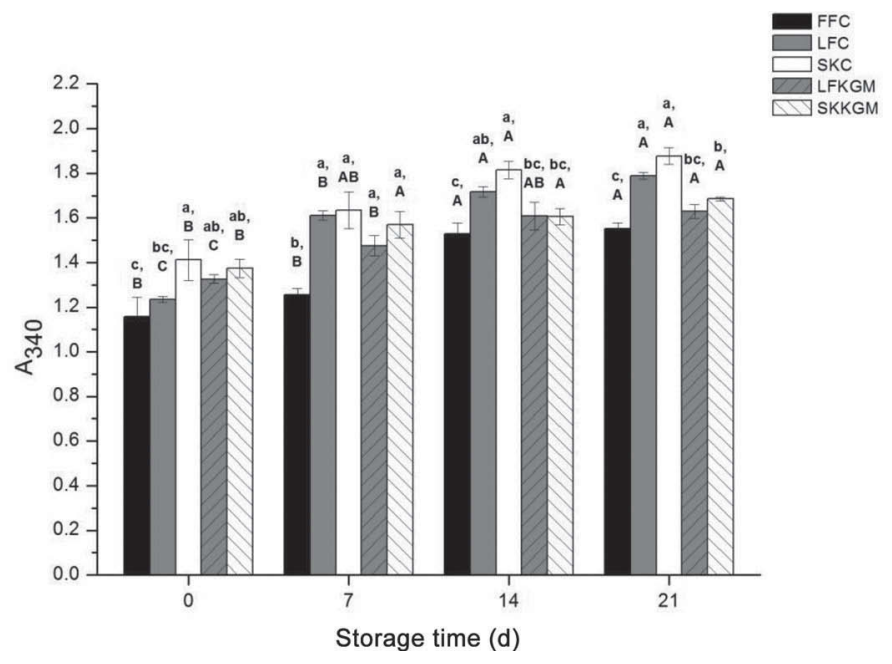

Figure 1. Changes in proteolysis (absorbance at $340 \mathrm{~nm} ; \mathrm{A}_{340}$ ) of yogurts during $21 \mathrm{~d}$ of storage at $4^{\circ} \mathrm{C}$. Values are expressed as mean \pm $\mathrm{SD}, \mathrm{n}=3 . \mathrm{KGM}=$ konjac glucomannan; $\mathrm{FFC}=$ full-fat yogurt control; LFC = low-fat yogurt control; SKC = skimmed yogurt control; LFKGM = low-fat yogurt with KGM; SKKGM = skimmed yogurt with KGM. Means of the yogurt sample at the same storage time without common letters $(\mathrm{a}-\mathrm{c})$ are significantly different $(P<0.05)$. Means of the same yogurt sample stored for different days without common letters $(\mathrm{A}-\mathrm{C})$ are significantly different $(P<0.05)$.

tionally, centrifugation might break the binding of free water with KGM and subsequently resulted in releasing the water from yogurt as whey. All these complicated factors may be the reason why KGM did not increase WHC in yogurts in our study. The WHC of LFC was stable and for those of other yogurt samples WHC increased at $\mathrm{d} 21$ as compared with that at $\mathrm{d} 0$. The WHC of FFC was stable over $14 \mathrm{~d}$ storage and increased at d 21, whereas that of SKKGM increased at d 7 and was stable after that. For other yogurt samples, WHC increased slightly during storage. The results were in agreement with those of Sahan et al. (2008) and Guven et al. (2005) that addition of $\beta$-glucan hydrocolloidal composite or inulin did not change the WHC of nonfat yogurts or set-type low-fat yogurts reported in their papers, respectively.

Syneresis. Syneresis represents the level of whey separated from yogurts under the influence of gravity (Amatayakul et al., 2006). Similar to the WHC results, syneresis of FFC was the lowest, whereas those of SKC were the highest among the yogurt samples during 21 $\mathrm{d}$ of storage (Figure 3). Results of FFC, LFC, and SKC indicated that fat contents in yogurts could be a reason to determine the syneresis. In addition to the fat content in yogurt, another reason why FFC had the lowest syneresis may be because of its higher TS compared with other samples (Harwalkar and Kalab, 1986). Syneresis values of LFKGM were lower than those of LFC during $21 \mathrm{~d}$ of storage, but were not different compared 


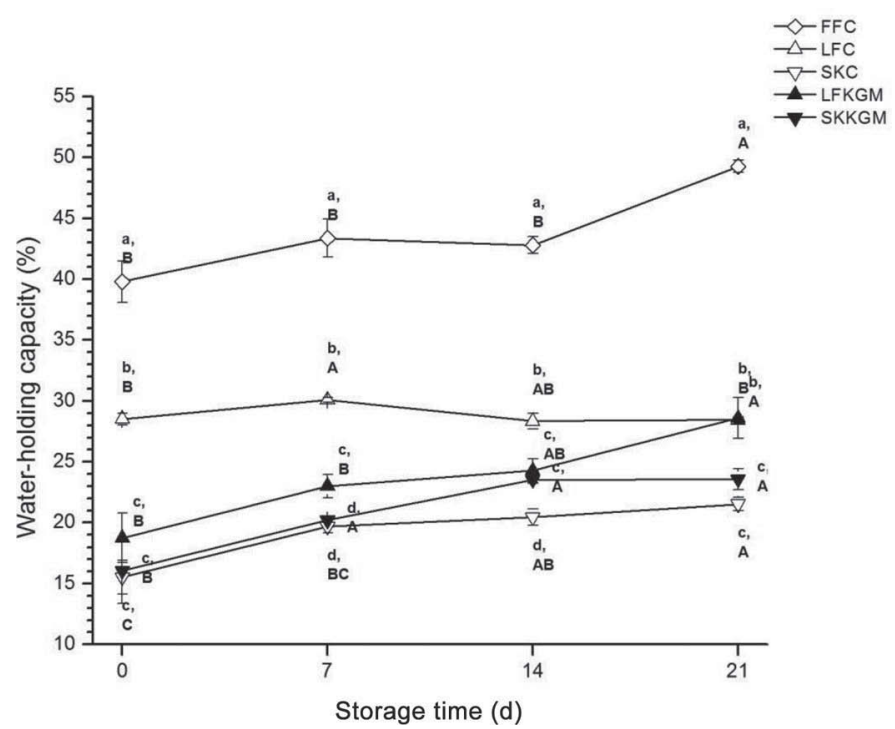

Figure 2. Water-holding capacities of yogurts measured by centrifugation method during $21 \mathrm{~d}$ of storage at $4^{\circ} \mathrm{C}$. Values are expressed as mean $\pm \mathrm{SD}, \mathrm{n}=3 . \mathrm{KGM}=$ konjac glucomannan; $\mathrm{FFC}=$ full-fat yogurt control; $\mathrm{LFC}=$ low-fat yogurt control; $\mathrm{SKC}=$ skimmed yogurt control; LFKGM = low-fat yogurt with KGM; SKKGM = skimmed yogurt with KGM. Means of the yogurt sample at the same storage time without common letters $(\mathrm{a}-\mathrm{d})$ are significantly different $(P$ $<0.05)$. Means of the same yogurt sample stored for different days without common letters $(\mathrm{A}-\mathrm{C})$ are significantly different $(P<0.05)$.

with LFC at d 0 and 7. Similarly, overall syneresis of SKKGM was lower than SKC during storage, but had no significant differences with SKC at d 7 and 14. The results indicated that the addition of KGM in low-fat or skimmed yogurt could partly decrease the syneresis of yogurts. This may be because of the high WHC of KGM that could absorb the whey released by the gel. A similar observation was reported by García-Pérez et al. (2005), that syneresis decreased when $1 \%$ orange fiber was added because of the high water-holding capability of the fiber. Syneresis of all the yogurt samples decreased at d 21 compared with those at d 0. However, the syneresis of FFC, LFC, and SKC was stable during storage, and that of LFKGM and SKKGM decreased at $\mathrm{d} 7$ compared with that at $\mathrm{d} 0$ and then kept stable during storage. The difference in WHC and syneresis detected from each method suggests that these methods measured different data. The whey was separated by gravity in this study. The centrifugation method is likely to accelerate the phase separation between milk protein and polysaccharide in yogurt as mentioned above, and gravity is a slow and gentle force to act on yogurts compared with that of centrifugation force. Gravity is not strong enough to break the cross-linking between milk protein and KGM, and also the binding between KGM and free water in yogurt. Guven et al. (2005) reported that syneresis of low-fat yogurt was

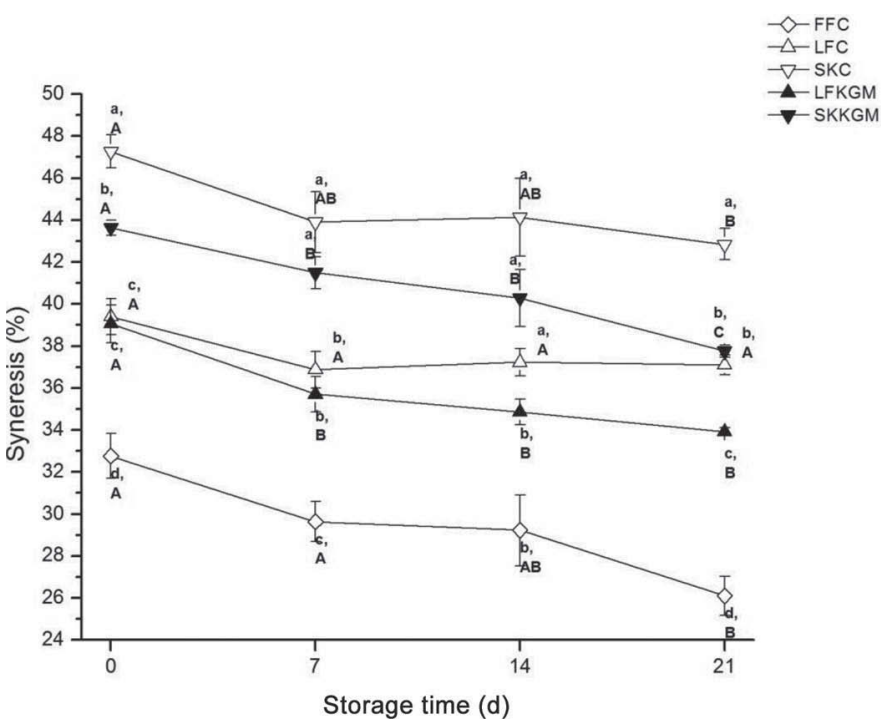

Figure 3. Index of syneresis of yogurts measured by drainage method during $21 \mathrm{~d}$ of storage at $4^{\circ} \mathrm{C}$. Values are expressed as mean \pm $\mathrm{SD}, \mathrm{n}=3 . \mathrm{KGM}=$ konjac glucomannan; $\mathrm{FFC}=$ full-fat yogurt control; LFC = low-fat yogurt control; $\mathrm{SKC}=$ skimmed yogurt control; LFKGM = low-fat yogurt with KGM; SKKGM = skimmed yogurt with KGM. Means of the yogurt sample at the same storage time without common letters $(\mathrm{a}-\mathrm{d})$ are significantly different $(P<0.05)$. Means of the same yogurt sample stored for different days without common letters $(\mathrm{A}-\mathrm{C})$ are significantly different $(P<0.05)$.

reduced with inulin addition during storage, which was similar to our results.

Spontaneous Whey Separation. Spontaneous whey separation represents the level of spontaneous whey separated on the surface of yogurt gels (Amatayakul et al., 2006). The SWS of FFC were the lowest among the yogurt samples during $21 \mathrm{~d}$ of storage (Figure 4). In general, the SWS decreased due to an increase in solids content (Amatayakul et al., 2006), this may be the reason why FFC had the lowest SWS. The LFC and SKC, which had similar TS contents, did not differ in SWS during $21 \mathrm{~d}$ of storage, whereas LFKGM and SKKGM were similar to each other at d 7, 14, and 21. These results illustrated that the fat content had no obvious effect on SWS for reduced-fat yogurt. The SWS of LFKGM was lower than that of LFC during storage and had no significant differences with FFC at $\mathrm{d} 7,14$, and 21 , which indicated the KGM addition in low-fat yogurt could decrease the whey separated from yogurt surface spontaneously similar to the SWS of full-fat yogurt. Similar results were reported by Miao et al. (2011) that yogurts with addition of water-soluble polysaccharides from truffles had lower SWS than yogurts without the polysaccharides. Sahan et al. (2008) also reported that addition of $\beta$-glucan composite to skimmed yogurt caused a decrease in SWS values. The addition of KGM in skimmed yogurt did not change 


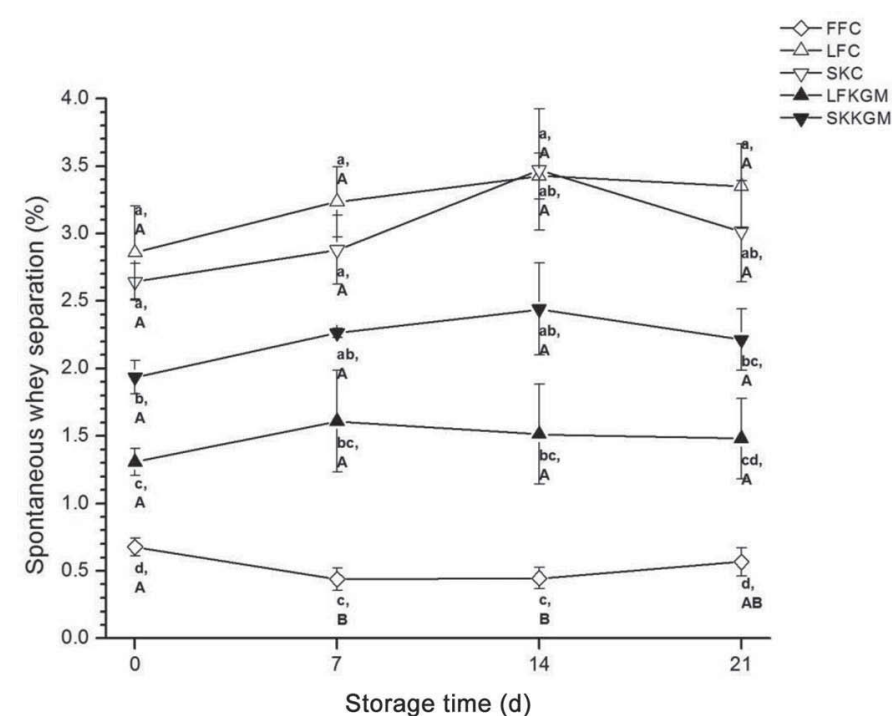

Figure 4. Spontaneous whey separation of yogurts measured by siphon method during $21 \mathrm{~d}$ of storage at $4^{\circ} \mathrm{C}$. Values are expressed as mean $\pm \mathrm{SD}, \mathrm{n}=3$. KGM = konjac glucomannan; $\mathrm{FFC}=$ full-fat yogurt control; LFC = low-fat yogurt control; SKC = skimmed yogurt control; LFKGM = low-fat yogurt with KGM; SKKGM = skimmed yogurt with KGM. Means of the yogurt sample at the same storage time without common letters $(\mathrm{a}-\mathrm{d})$ are significantly different $(P$ $<0.05)$. Means of the same yogurt sample stored for different days without common letters $(\mathrm{A}, \mathrm{B})$ are significantly different $(P<0.05)$.

the SWS much as the results showed no significant differences between SKC and SKKGM at d 7, 14, and 21. The changes of SWS in all the yogurt samples were not significant during $21 \mathrm{~d}$ of storage, except FFC had a decreased SWS value at $d$ 7. Similar results were observed by Ramchandran and Shah (2010) for the low-fat yogurts.

\section{Texture}

The FFC had higher firmness and consistency, and more negative cohesiveness and viscosity index than all of the other yogurt samples, whereas the lowest firmness and consistency, and the least negative cohesiveness and viscosity index were observed for SKC throughout the $21 \mathrm{~d}$ of storage (Table 4). Additionally, SKKGM had higher firmness, consistency, cohesiveness (negative), and viscosity index (negative) than SKC during storage. However, the textural characteristics of LFC, LFKGM, and SKKGM were not significantly different among each other over $21 \mathrm{~d}$ of storage. The KGM addition to yogurt had positive effects on the textural characteristics of the skimmed yogurts, but was ineffective for the low-fat yogurts. This may be because of the complicated interaction between protein, fat, and polysaccharide during fermentation. Similar results were reported by Ramchandran and Shah (2009) that the inclusion of inulin to low-fat yogurt prepared with exopolysaccharide-producing cultures did not influence the firmness.

No significant variation was found in the firmness of FFC, SKC, and LFKGM throughout the storage period, whereas that of LFC and SKKGM increased at d 21 and 7 , respectively. Consistency and cohesiveness (negative) of all the yogurt samples kept stable, except that of SKKGM increased at $d$ 7. Index of viscosity of FFC, LFC, LFKGM, and SKKGM was stable, whereas that of SKC became more negative during $21 \mathrm{~d}$ of storage. Similar results were observed and explained by Seçkin and Baladura (2012). In their study, the storage did not affect viscosity index values of all yogurt samples with addition of different fibers, and the changes in cohesiveness and consistency did not follow any particular pattern during storage, likely due to the complicated physical, biochemical, and chemical reactions occurring during the storage. This might also be the reason for the results achieved in our study.

\section{Microscopic Structure}

Structures of yogurts observed by CLSM at d 0 and 21 are shown in Figure 5. Denser protein aggregates appeared light green, and the black areas represented serum pores (Cruz et al., 2009; Nguyen et al., 2014; Li and Shah, 2015). All the yogurt samples at d 0 showed homogeneous structures containing small serum pores. Folkenberg et al. (2006) reported that yogurts should have medium-size pores in the matrix to provide stable structures. However, SKC had more and larger areas of serum pores than other yogurt samples, which may be because of the higher whey expulsion from the yogurts that were observed in the Expulsion of Serum section. The serum pores were less and smaller in LFKGM and SKKGM compared with those of LFC and SKC, indicating the stronger and more stable gel structures in LFKGM and SKKGM. Galesloot (1958) and Ciron et al. (2010) reported that the weak gel structure (firmness) of yogurt contributed to its low viscosity and low water retention. Weak gels had a strong tendency to flow and were more prone to shrinkage and whey expulsion (Pereira et al., 2003; Serra et al., 2008). Thus, the stronger and more stable structures of LFKGM and SKKGM may be attributed to the higher viscosity of KGM and subsequent higher viscosity of yogurts. Additionally, the structures may due to high water-holding capability of KGM and subsequent less whey expulsion from the yogurts.

After $21 \mathrm{~d}$ of storage, microscopic structures showed much larger areas of serum pores in FFC, LFC, and SKC compared with those at $\mathrm{d} 0$. The protein aggregated and small serum pores that formed at d 0 could 
stimulate later protein aggregation in the yogurts during storage (Li and Shah, 2015). Additionally, LFKGM and SKKGM showed denser protein matrix at $\mathrm{d} 21$ than $\mathrm{d} 0$, and the serum pores at $\mathrm{d} 21$ were similarly homogeneous and medium-size as those at $\mathrm{d} 0$. The sizes of serum pores in yogurts at d 21 were in the order of $\mathrm{SKC}>\mathrm{LFC}>\mathrm{FFC}>\mathrm{SKKGM}>\mathrm{LFKGM}$, which indicated that the reduction of fat content in yogurt negatively influenced the stability of gel structures, whereas the addition of KGM could enhance the stability of gel structures. The results accorded with Ciron et al. (2010) and Lanciotti et al. (2004), who reported that the texture and stability of yogurt primarily depended on the levels of TS, fat, and protein. Guggisberg et al. (2009) reported that additional inulin accelerated the protein aggregation in set yogurt with the increasing concentrations of inulin. Additionally, in the study of $\mathrm{Li}$ and Shah (2015), the fermented milk with addition of polysaccharide extracted from Pleurotus eryngii at different levels showed denser protein aggregates and contained larger serum pores than that of fermented milk without $P$. eryngii during $21 \mathrm{~d}$ of refrigerated storage. Similarly, our previous work (unpublished data) showed that the aggregation of milk and KGM increased with the increasing concentrations of KGM in milk-KGM mixtures before fermentation. When the concentration of KGM solution was more than $0.5 \%$, a metastable or unstable structure of the milk-KGM mixtures induced by the aggregation of the milk and KGM particles would be observed at the level of 95\% (vol:vol) milk. However, the additional KGM improved the structures of low-fat and skimmed yogurt during $21 \mathrm{~d}$ of storage because the KGM-milk mixtures used in this study had a stable structure in which the concentration of KGM solution was $0.5 \%$. Moreover, the high water holding capability of KGM and the subsequent lower whey expulsion and improved textural attributes observed in the Expulsion of Serum and Texture sections might be other factors that improved the CLSM structures in LFKGM and SKKGM during $21 \mathrm{~d}$ of storage.

\section{CONCLUSIONS}

The addition of KGM in low-fat or skimmed yogurt did not affect the composition or the changes of $\mathrm{pH}$ and TA during storage. However, yogurts with additional KGM had higher whiteness, greenness, and yellowness hues compared with those without KGM. The presence of KGM weakened the proteolytic capability in yogurts, but provided similar proteolysis as in full-fat yogurt

Table 4. Texture attributes of yogurts during $21 \mathrm{~d}$ of storage at $4^{\circ} \mathrm{C}^{1}$

\begin{tabular}{|c|c|c|c|c|}
\hline Sample $^{2}$ & \multicolumn{4}{|c|}{ Period of storage (d) } \\
\hline \multicolumn{5}{|c|}{ Firmness (g) } \\
\hline LFC & $79.82 \pm 3.68^{\mathrm{bc}, \mathrm{B}}$ & $81.93 \pm 2.52^{\mathrm{b}, \mathrm{B}}$ & $81.07 \pm 5.48^{\mathrm{bc}, \mathrm{B}}$ & $83.55 \pm 9.36^{\mathrm{abc}, \mathrm{A}}$ \\
\hline SKC & $68.27 \pm 2.94^{\mathrm{c}, \mathrm{A}}$ & $66.71 \pm 0.86^{\mathrm{c}, \mathrm{A}}$ & $73.22 \pm 2.38^{\mathrm{c}, \mathrm{A}}$ & $73.94 \pm 4.09^{\mathrm{c}, \mathrm{A}}$ \\
\hline LFKGM & $82.25 \pm 2.75^{\mathrm{b}, \mathrm{A}}$ & $85.91 \pm 5.71^{\mathrm{b}, \mathrm{A}}$ & $89.14 \pm 2.08^{\mathrm{b}, \mathrm{A}}$ & $88.31 \pm 5.68^{\mathrm{bc}, \mathrm{A}}$ \\
\hline LFC & $1,730.25 \pm 24.79^{\mathrm{bc}, \mathrm{A}}$ & $1,825.79 \pm 79.69^{\mathrm{b}, \mathrm{A}}$ & $1,756.53 \pm 129.24^{\mathrm{bc}, \mathrm{A}}$ & $1,855.75 \pm 90.42^{\mathrm{c}, \mathrm{A}}$ \\
\hline $\mathrm{SKC}$ & $1,518.93 \pm 147.17^{\mathrm{c}, \mathrm{B}}$ & $1,540.45 \pm 68.68^{\mathrm{c}, \mathrm{AB}}$ & $1,705.85 \pm 86.52^{\mathrm{c}, \mathrm{AB}}$ & $1,788.00 \pm 44.95^{\mathrm{c}, \mathrm{A}}$ \\
\hline LFKGM & $1,906.06 \pm 81.62^{\mathrm{b}, \mathrm{A}}$ & $1,981.75 \pm 44.78^{\mathrm{b}, \mathrm{A}}$ & $2,080.40 \pm 24.29^{\mathrm{ab}, \mathrm{A}}$ & $2,036.93 \pm 97.93^{\mathrm{bc}, \mathrm{A}}$ \\
\hline SKKGM & $1,852.30 \pm 13.78^{\mathrm{b}, \mathrm{B}}$ & $2,164.84 \pm 119.09^{\mathrm{b}, \mathrm{A}}$ & $2,150.01 \pm 157.23^{\mathrm{bc}, \mathrm{AB}}$ & $2,258.94 \pm 120.40^{\mathrm{b}, \mathrm{A}}$ \\
\hline \multicolumn{5}{|c|}{ Cohesiveness (g) } \\
\hline FFC & $-46.99 \pm 0.51^{\mathrm{c}, \mathrm{A}}$ & $-46.39 \pm 1.03^{\mathrm{c}, \mathrm{A}}$ & $-47.62 \pm 0.71^{\mathrm{c}, \mathrm{A}}$ & $-46.91 \pm 1.41^{\mathrm{c}, \mathrm{A}}$ \\
\hline FFC & $-54.31 \pm 5.75^{\mathrm{c}, \mathrm{A}}$ & $-43.10 \pm 4.62^{\mathrm{c}, \mathrm{A}}$ & $-52.88 \pm 7.98^{\mathrm{c}, \mathrm{A}}$ & $-53.26 \pm 4.34^{\mathrm{c}, \mathrm{A}}$ \\
\hline LFC & $-22.85 \pm 1.26^{\mathrm{b}, \mathrm{A}}$ & $-25.41 \pm 5.03^{\mathrm{ab}, \mathrm{A}}$ & $-18.89 \pm 1.96^{\mathrm{a}, \mathrm{A}}$ & $-26.34 \pm 4.36^{\mathrm{ab}, \mathrm{A}}$ \\
\hline SKC & $-6.73 \pm 1.90^{\mathrm{a}, \mathrm{A}}$ & $-4.16 \pm 0.36^{\mathrm{a}, \mathrm{A}}$ & $-14.87 \pm 1.53^{\mathrm{a}, \mathrm{C}}$ & $-10.16 \pm 0.03^{\mathrm{a}, \mathrm{B}}$ \\
\hline LFKGM & $-27.13 \pm 2.31^{\mathrm{b}, \mathrm{A}}$ & $-28.81 \pm 2.99^{\mathrm{bc}, \mathrm{A}}$ & $-30.63 \pm 0.17^{\mathrm{b}, \mathrm{A}}$ & $-30.07 \pm 2.42^{\mathrm{b}, \mathrm{A}}$ \\
\hline SKKGM & $-24.90 \pm 1.97^{\mathrm{b}, \mathrm{A}}$ & $-30.70 \pm 3.73^{\mathrm{bc}, \mathrm{A}}$ & $-33.39 \pm 3.02^{\mathrm{b}, \mathrm{A}}$ & $-31.43 \pm 4.65^{\mathrm{b}, \mathrm{A}}$ \\
\hline
\end{tabular}



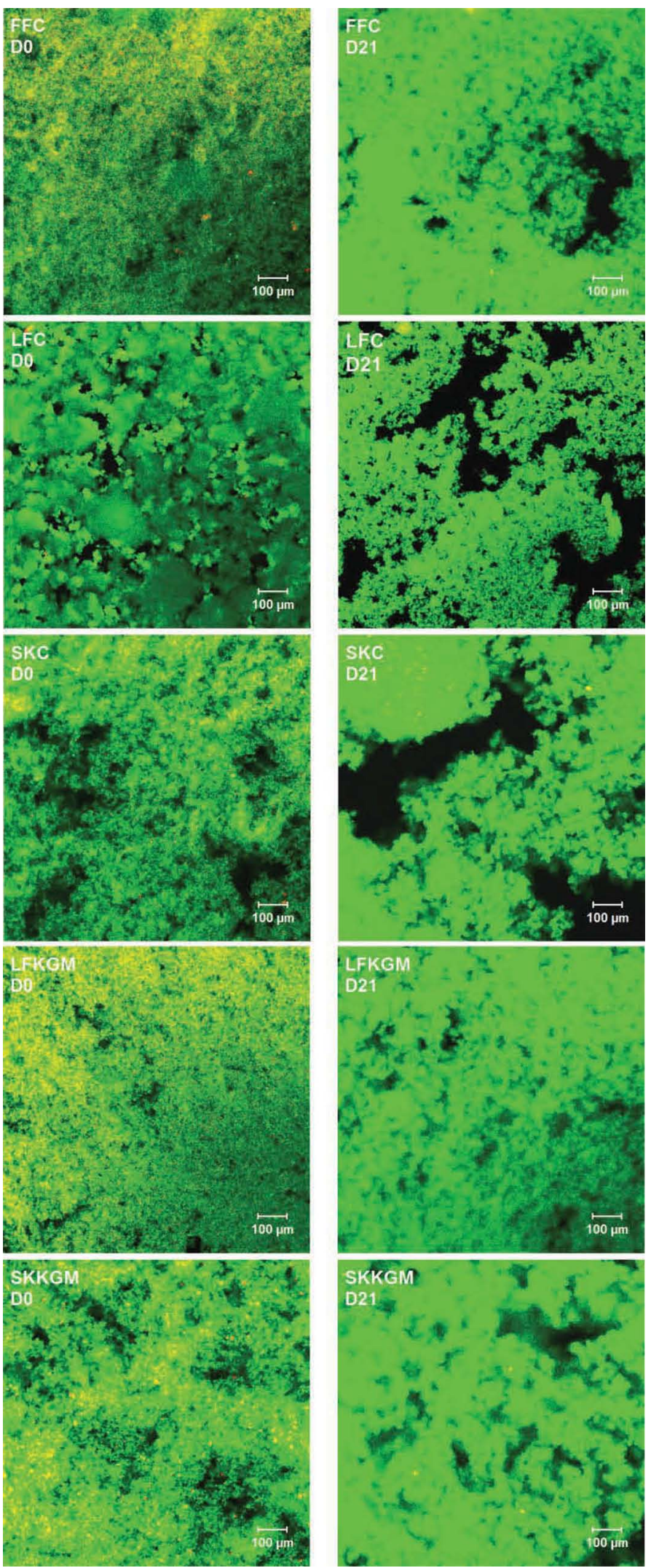

Figure 5. Confocal laser scanning microscopy (CLSM) of yogurts at d 0 and $21 . \mathrm{FFC}=$ full-fat yogurt control; LFC $=$ low-fat yogurt control; SKC = skimmed yogurt control; LFKGM = low-fat yogurt with KGM; SKKGM = skimmed yogurt with KGM; KGM = konjac glucomannan . 
after $14 \mathrm{~d}$ of storage. The KGM added to yogurts had no positive effect on WHC, but could decrease the syneresis and SWS during storage; the SWS of LFKGM was similar to those of FFC during storage. Textural characteristics were positively influenced by additional KGM in skimmed yogurt, but no effects were found in low-fat yogurt. Additional KGM improved the structures of yogurts during storage, as the yogurt with KGM showed stronger and more stable gel structures than that of control yogurts. Overall, the storage time had no substantial effects on the characteristics of the yogurts except the gel structures. Our study indicated that KGM may be considered as a fat replacer added to milk before fermentation to improve the characteristics and health benefits of reduced-fat yogurts.

\section{REFERENCES}

Abhyankar, A. R., D. M. Mulvihill, V. Chaurin, and M. A. Auty. 2011. Techniques for localisation of konjac glucomannan in model milk protein-polysaccharide mixed systems: Physicochemical and microscopic investigations. Food Chem. 129:1362-1368.

Amatayakul, T., F. Sherkat, and N. P. Shah. 2006. Syneresis in set yogurt as affected by EPS starter cultures and levels of solids. Int. J. Dairy Technol. 59:216-221.

AOAC International. 1999. Official Methods of Analysis. Vol. II. 5th rev. AOAC Int., Rockville, MD.

Aziznia, S., A. Khosrowshahi, A. Madadlou, and J. Rahimi. 2008. Whey protein concentrate and gum tragacanth as fat replacers in nonfat yogurt: Chemical, physical, and microstructural properties. J. Dairy Sci. 91:2545-2552.

Barrantes, E., A. Y. Tamime, G. Davies, and M. N. Barclay. 1994. Production of low-calorie yogurt using skim milk powder and fatsubstitutes. 2. Compositional quality. Milchwissenschaft 49:135139.

Beal, C., J. Skokanova, E. Latrille, N. Martin, and G. Corrieu. 1999. Combined effects of culture conditions and storage time on acidification and viscosity of stirred yogurt. J. Dairy Sci. 82:673-681.

Brennan, C. S., and C. M. Tudorica. 2008. Carbohydrate-based fat replacers in the modification of the rheological, textural and sensory quality of yoghurt: Comparative study of the utilisation of barley beta-glucan, guar gum and inulin. Int. J. Food Sci. Technol. 43:824-833.

Chua, M., T. C. Baldwin, T. J. Hocking, and K. Chan. 2010. Traditional uses and potential health benefits of Amorphophallus konjac K. Koch ex NE Br. J. Ethnopharmacol. 128:268-278.

Church, F. C., H. E. Swaisgood, D. H. Porter, and G. L. Catignani. 1983. Spectrophotometric assay using o-phthaldialdehyde for determination of proteolysis in milk and isolated milk proteins. J. Dairy Sci. 66:1219-1227.

Ciron, C. I. E., V. L. Gee, A. L. Kelly, and M. A. E. Auty. 2010. Comparison of the effects of high-pressure microfluidization and conventional homogenization of milk on particle size, water retention and texture of non-fat and low-fat yoghurts. Int. Dairy J. 20:314-320.

Cruz, N. S., M. Capellas, D. P. Jaramillo, A. J. Trujillo, B. Guamis, and V. Ferragut. 2009. Soymilk treated by ultra high-pressure homogenization: Acid coagulation properties and characteristics of a soy-yogurt product. Food Hydrocoll. 23:490-496.

Deeth, H. C., and A. Y. Tamime. 1981. Yogurt: nutritive and therapeutic aspects. J. Food Prot. 44:78-86.

Dinkci, N. 2012. The influence of transglutaminase treatment on functional properties of strained yoghurt. J. Anim. Vet. Adv. 11:22382246 .
Erdman, M. D., W. G. Bergen, and C. A. Reddy. 1977. Amino acid profiles and presumptive nutritional assessment of single-cell protein from certain lactobacilli. Appl. Environ. Microbiol. 33:901905.

Fang, W., and P. Wu. 2004. Variations of konjac glucomannan (KGM) from Amorphophallus konjac and its refined powder in China. Food Hydrocoll. 18:167-170.

Folkenberg, D. M., P. Dejmek, A. Skriver, and R. Ipsen. 2006. Interactions between EPS-producing Streptococcus thermophilus strains in mixed yoghurt cultures. J. Dairy Res. 73:385-393.

Galesloot, T. E. 1958. Investigations concerning the consistency of yogurt. Neth. Milk Dairy J. 12:130-165.

García-Pérez, F. J., Y. Lario, J. Fernández-López, E. Sayas, J. A. Pérez-Alvarez, and E. Sendra. 2005. Effect of orange fiber addition on yogurt color during fermentation and cold storage. Color Res. Appl. 30:457-463.

Guggisberg, D., J. Cuthbert-Steven, P. Piccinali, U. Bütikofer, and P. Eberhard. 2009. Rheological, microstructural and sensory characterization of low-fat and whole milk set yoghurt as influenced by inulin addition. Int. Dairy J. 19:107-115.

Guven, M., K. Yasar, O. B. Karaca, and A. A. Hayaloglu. 2005. The effect of inulin as a fat replacer on the quality of set-type low-fat yogurt manufacture. Int. J. Dairy Technol. 58:180-184.

Harwalkar, V. R., and M. Kalab. 1986. Relationship between microstructure and susceptibility to syneresis in yoghurt made from reconstituted nonfat dry milk. Food Microstructure 5:287-294.

James, T. K., and J. M. Follett. 2000. Herbicides for weed control in the root crops Ullucus tuberosus and Amorphophallus konjac. Pages 289-292 in Proc. New Zealand Plant Protection Conference. N. Z. Plant Prot., 1998, Palmerston North, New Zealand.

Kato, K., and K. Matsuda. 1969. Studies on the chemical structure of konjac mannan. Agric. Biol. Chem. 33:1446-1453.

Keogh, M. K., and B. T. O'Kennedy. 1998. Rheology of stirred yogurt as affected by added milk fat, protein and hydrocolloids. J. Food Sci. 63:108-112.

Kraemer, W. J., J. L. Vingren, R. Silvestre, B. A. Spiering, D. L. Hatfield, J. Y. Ho, M. S. Fragala, C. M. Maresh, and J. S. Volek. 2007. Effect of adding exercise to a diet containing glucomannan. Metabolism 56:1149-1158.

Lanciotti, R., L. Vannini, P. Pittia, and M. E. Guerzoni. 2004. Suitability of high-dynamic-pressure-treated milk for the production of yoghurt. Food Microbiol. 21:753-760.

Li, B., J. Xia, Y. Wang, and B. Xie. 2005. Grain-size effect on the structure and antiobesity activity of konjac flour. J. Agric. Food Chem. 53:7404-7407.

Li, S., and N. P. Shah. 2015. Effects of Pleurotus eryngii polysaccharides on bacterial growth, texture properties, proteolytic capacity, and angiotensin-I-converting enzyme-inhibitory activities of fermented milk. J. Dairy Sci. 98:2949-2961.

Lobato-Calleros, C., C. Ramírez-Santiago, E. J. Vernon-Carter, and J. Alvarez-Ramirez. 2014. Impact of native and chemically modified starches addition as fat replacers in the viscoelasticity of reducedfat stirred yogurt. J. Food Eng. 131:110-115.

Lucey, J. A., P. A. Munro, and H. Singh. 1998. Whey separation in acid skim milk gels made with glucono- $\delta$-lactone: Effects of heat treatment and gelation temperature. J. Texture Stud. 29:413-426.

Miao, Y. Z., Q. Lin, Y. Cao, G. H. He, D. R. Qiao, and Y. Cao. 2011. Extraction of water-soluble polysaccharides (WSPS) from Chinese truffle and its application in frozen yogurt. Carbohydr. Polym. $86: 566-573$.

Nguyen, H. T. H., L. Ong, C. Lefèvre, S. E. Kentish, and S. L. Gras, 2014. The microstructure and physicochemical properties of probiotic buffalo yoghurt during fermentation and storage: A comparison with bovine yoghurt. Food Bioprocess Technol. 7:937-953.

Nishinari, K., P. A. Williams, and G. O. Phillips. 1992. Review of the physico-chemical characteristics and properties of konjac mannan. Food Hydrocoll. 6:199-222.

Park, J. W. 1996. Temperature-tolerant fish protein gels using konjac flour. J. Muscle Foods 7:165-174. 
Park, Y. W. 2000. Comparison of mineral and cholesterol composition of different commercial goat milk products manufactured in USA. Small Rumin. Res. 37:115-124.

Pereira, R. B., H. Singh, P. A. Munro, and M. S. Luckman. 2003. Sensory and instrumental textural characteristics of acid milk gels. Int. Dairy J. 13:655-667.

Perols, C., B. Piffaut, J. Scher, J. P. Ramet, and D. Poncelet. 1997. The potential of enzyme entrapment in konjac cold-melting gel beads. Enzyme Microb. Technol. 20:57-60.

Ramchandran, L., and N. P. Shah. 2009. Effect of exopolysaccharides and inulin on the proteolytic, angiotensin-I-converting enzymeand $\alpha$-glucosidase-inhibitory activities as well as on textural and rheological properties of low-fat yogurt during refrigerated storage. Dairy Sci. Technol. 89:583-600.

Ramchandran, L., and N. P. Shah. 2010. Characterization of functional, biochemical and textural properties of synbiotic low-fat yogurts during refrigerated storage. LWT Food Sci. Technol. 43:819-827.

Sahan, N., K. Yasar, and A. A. Hayaloglu. 2008. Physical, chemical and flavour quality of non-fat yogurt as affected by a $\beta$-glucan hydrocolloidal composite during storage. Food Hydrocoll. 22:12911297.

Sanz, T., A. Salvador, A. Jimenez, and S. M. Fiszman. 2008. Yogurt enrichment with functional asparagus fibre. Effect of fibre extraction method on rheological properties, colour, and sensory acceptance. Eur. Food Res. Technol. 227:1515-1521.

Seçkin, A. K., and E. Baladura. 2012. Effect of using some dietary fibers on color, texture and sensory properties of strained yogurt. GIDA 37:63-69.
Serra, M., A. J. Trujillo, P. D. Jaramillo, and B. Guamis. 2008. Ultrahigh pressure homogenization-induced changes in skim milk: Impact on acid coagulation properties. J. Dairy Res. 75:69-75.

Shihata, A., and N. P. Shah. 2000. Proteolytic profiles of yogurt and probiotic bacteria. Int. Dairy J. 10:401-408.

Tamime, A. Y., E. Barrantes, and A. M. Sword. 1996. The effect of starch based fat substitutes on the microstructure of set-style yogurt made from reconstituted skimmed milk powder. Int. J. Dairy Technol. 49:1-10.

Tamime, A. Y., and R. K. Robinson. 1999. Yogurt: Science and Technology. 2nd ed. CRC Press, New York, NY.

Ünal, B., S. Metin, and N. D. Iş̧ılı. 2003. Use of response surface methodology to describe the combined effect of storage time, locust bean gum and dry matter of milk on the physical properties of low-fat set yoghurt. Int. Dairy J. 13:909-916.

Vanderbeek, P. B., C. Fasano, G. O'Malley, and J. Hornstein. 2007. Esophageal obstruction from a hygroscopic pharmacobezoar containing glucomannan. Clin. Toxicol. (Phila) 45:80-82.

Vuksan, V., D. J. A. Jenkins, P. Spadafora, J. L. Sievenpiper, R. Owen, E. Vidgen, F. Brighenti, R. Josse, L. A. Leiter, and C. Bruce-Thompson. 1999. Konjac-mannan (glucomannan) improves glycemia and other associated risk factors for coronary heart disease in type 2 diabetes. A randomized controlled metabolic trial. Diabetes Care 22:913-919.

Zare, F., J. I. Boye, V. Orsat, C. Champagne, and B. K. Simpson. 2011. Microbial, physical and sensory properties of yogurt supplemented with lentil flour. Food Res. Int. 44:2482-2488. 